\title{
EXISTING-BIM: INTEGRATED SURVEY PROCEDURES FOR THE MANAGEMENT OF MODERN ARCHITECTURE
}

\author{
S. Monaco ${ }^{1}$, M. Siconolfi ${ }^{1}$, A. di Luggo ${ }^{1}$ \\ ${ }^{1}$ Department of Architecture University of Naples Federico II \\ (stefaniamonaco.90@alice.it; mirkosico@live.it; antonella.diluggo@unina.it)
}

\section{Commission II}

KEY WORDS: e-bim, h-bim, image-based survey, data processing, database modeling

\begin{abstract}
This paper is aimed at illustrating the operation workflow to create a BIM model of an existing building, by highlighting its process starting from photogrammetric acquisitions and indicating its critical elements as regards data structure and the following modeling. The subject of this study is a reinforced concrete building of the 1960s on six levels. At present, it is undergoing an extensive refurbishment with the purpose of converting its original function, from the US Navy Hospital into offices. Since it was possible to access archive documents concerning the executive design and to carry out even invasive surveys for acquiring specific data about building details, BIM modeling could refer to a significant amount of qualitative and quantitative data. This circumstance characterized the work steps of a BIM modeling which, although referred to an existing building, may also be applied to new constructions. Building technology has implicitly facilitated the identification of the constructive elements and the creation of a list, although the unusual shape of the structure has caused specific problems differently discussed and documented in the text.
\end{abstract}

\section{INTRODUCTION}

Technological development has opened new perspectives in the survey of architectural heritage, giving the possibility to acquire vast amounts of data even in a very short time. This evolution needs competence in the use of new tools, in order to optimize processes and to achieve reliable data. At present, in fact, data quality has a primary role, considering the diffusion of remote collaboration in more and more open and shared fields. The quality of information and their digital representation very often plays a basic role prefiguring in cyberspace a copy of reality, with the possibility of virtually operating similarly to the physical space.

As it is well-known, this concerns BIM modeling, which reproduces real elements and processes in the digital space. This process is based on the interaction between several professional figures according to continuously shared data (Eastman et al., 2011). In fact, this technology involves a deep transformation of the operating procedures in building, both as regards new constructions and in survey and documentation of built heritage. Nevertheless, the transition to new technologies and procedures show some inertia, considering the professional commitment inherent in the revision of processes and project management. Anyway, in recent years, in many countries, the building sector has had to deal with the new rules about the introduction of digital shared processes in projecting and executing works with particular reference to new constructions.

In science, experimentally these processes also involve built heritage, by exploring ontological issues about the semantics of building elements (Quattrini et al., 2015), detail level and adherence of the model to the uniqueness of the single monument, graphic representations needed to achieve the objectives and the possible identification of an operating workflow (Osello, 2015; Oreni et al., 2014). In addition to these theoretical/methodological questions, operational issues are also taken into consideration, such as the absence of software for modeling existing and, in particular, historical buildings able to reproduce their form and content considering the uniqueness and the intrinsic value of the single artifacts. In this respect, it must be said that the approach can't be unique, because of the variety of morphologies and types of existing architectures: this leads to the necessity to find flexible operating procedures able to consider typical changes of existing architectural heritage with its anomalies caused by the irregularities of the construction phases and by the transformations over time.

The following study illustrates survey and BIM modeling of an existing building, using integrated data deriving from archive documents, photogrammetric investigations, and direct and even invasive surveys, considering that the contemporary construction phase involved the dismantling of many parts of the building with a view to a radical transformation of its function.

\section{CASE STUDY}

The subject of this study is a building of the 1960s (Figure 1), which is a compact block with a curvilinear plan. It covers an area of about 1,400 square meters and is 26 meters high, with a reinforced concrete structure, formed by the main body on six levels and, on the north-east side, a secondary low structure. At the present time, the building is undergoing a radical refurbishment in order to be transformed from Us Navy Hospital into offices. Therefore, survey and modeling started in an advanced construction phase with the concomitant demolition of all the indoor divisions allowing to survey the structural frames and the stratigraphy of some elements.

The dismantling of the building suggested to carry out a BIM modeling also with a view to more proper management of design and construction phases. In addition, the BIM model was very important even for energy analysis and seismic tests, in view of suitable management of the artifact once the refurbishment has been completed.

The condition was ideal because data can be modeled in line with BIM for new buildings and, therefore, bypassing the difficulties characteristics of BIM for existing architectural heritage. As it is well-known, when applied to historical built heritage, this process has many problems largely illustrated in the literature on this subject (Dore and Murphy, 2017; Logothetis et al., 2015; Scandurra et al., 2017; Oreni et al., 2013), which are linked to the complexity of elements and to the difficulty to conform to a morphologically complicated and often stratified structure. In fact, one of these problems is the dichotomy between the uniqueness of the element and the 
required adherence to standardized elements, just as it is difficult to survey technological and construction data and to identify the characteristics of elements. This condition would be likely to lead to modeling which scarcely conforms to the real artifact, especially with reference to analytical data, with the consequent difficulty of preparing reliable static or energy analysis. On the contrary, BIM modeling applied to new constructions is a linear process based on the knowledge and the direct correspondence between the designed elements and the built ones.

This case study is an intermediate technology, both for the type of construction, which allowed to recognize serial and standardized elements and for the possibility to carry out an exhaustive survey giving birth to a modeling in the field of EBIM or Existing BIM.

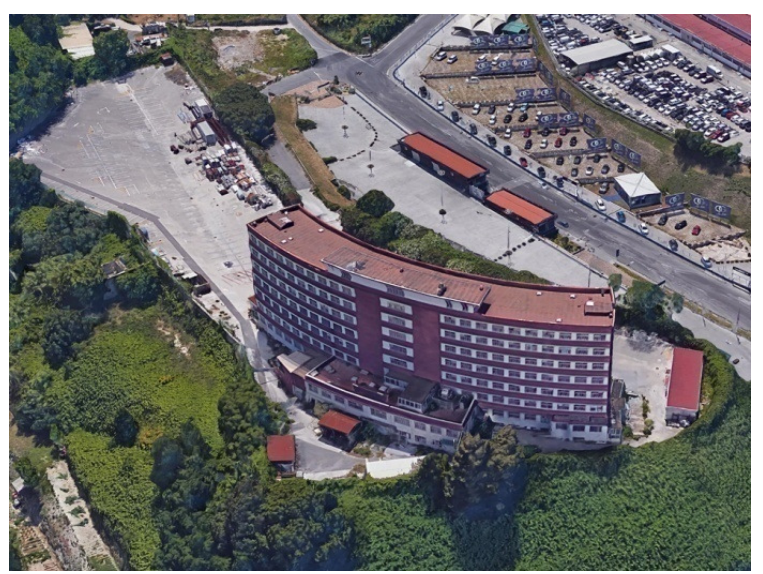

Figure 1: View of the building (Google Earth).

\section{OBJECTIVES}

This research is aimed at documenting the operating phases of data capture and the following parametric modeling, showing the process which allowed to obtain a database for the investigation of elements, the storage of images, the extraction of lists and the consultation of archive documents. In view of the future management of this building, a particular attention was given to those elements more subject to maintenance, such as pipes, connections, plants, furnishings, doors and windows, which are considered as a part of a collection of materic and metric information, as well as thermal and mechanic values related to the individual elements of the building envelope as a whole. In particular, it should be noted that for the creation of information models, it is very important to design the aims since work must be carried out according to some operating limits of software and taking into account that a generic model does not allow to create a product which meets all needs. In fact, some cases require a model less corresponding to the form, but more able to meet analytical needs; on the contrary, some other conditions require a greater correspondence to form at the expense of identity indications of the element.

\section{DATA CAPTURE AND ORGANIZATION}

The creation of the information model included many phases, in some cases structured in a sequential way, in other cases in a simultaneous and integrated manner.

The main steps were:

the collection and organization of archive data relating to the executive project of the 1960s; a comparison of data with sample measurements and with the point cloud of a standard plan;

a breakdown into elements:

the identification of specific information to be entered for each element;

modeling of the individual parts;

the construction of a reference project;

the unitary composition of the element.

It is a known fact that data organization determines the quality of the whole process. In this case, given the diversity of sources, it was necessary to carry out a work of standardization and synthesis. In fact, although very detailed, paper project drawings showed progress and variations sometimes not corresponding to what was built. At the same time, digital plans of a more recent survey did not include documents concerning details, even if more similar in some points. Therefore, in order to verify data, it was necessary to supplement pre-existing documents with another direct and photogrammetric survey.

In this respect, reference was made to a point cloud acquired with digital photogrammetry with regard to a standard level, for verifying the consistency with the paper documents of the relative position between the pillars and the external walls. Once the latter were proven to be reliable, all the levels were vectorized, by changing survey times in the site into sample controls of the height of each floor, the interaxes and the dimensions of pillars and beams.

\subsection{Photogrammetric survey}

Photogrammetry point cloud was used as a system of data control since it was particularly useful to verify the layout of the building structure.

In detail, in the campaign phase, 580 pictures were taken by an Olympus Pen E-PL1 Micro 4/3 camera with a 12MP sensor and data were processed by a Photoscan software for photomodeling which uses an SfM (Structure from Motion) algorithm. In fact, the usual acquisition process consists of obtaining a series of photos with the camera axis set in a directional orthogonal to elevations and with a certain overlap between the frames (De Luca, 2011; Remondino and El-Hakim, 2006).

Nevertheless, in order to reduce processing data and to obtain information not only about elevations but also floors and ceilings, a different acquisition mode was chosen, where the axis was not orthogonal but parallel to the indoor facades, with shooting pictures in the direction of the indoor corridor (Figure 2). This operation was carried out for every span, first in one direction and then in the other, to ensure the maximum efficiency.

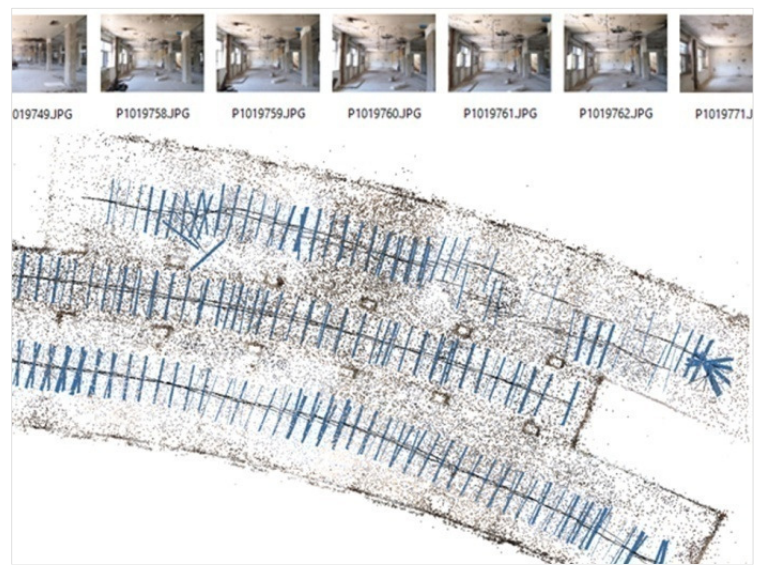

Figure 2: Plan view of a portion of the point cloud of a standard level, displayed in Photoscan. Photo plans are showed in blue. 
This kind of acquisition allowed to obtain a point cloud through the processing of a unique chunk, instead of individually processing different portions to be united in a second step. It should be noted that if on the one hand merging error between more chunks is eliminated, on the other hand, information acquired parallel to the camera axis tend to be less accurate (Dallagiacoma, 2016). In this case, this aspect was limited thanks to the superabundance of photos and to the specific shape of the building which has a curvilinear plan and, for this reason, in each photo implicitly allowed to acquire information about different levels, with particular reference to the position of pillars (Figures 3-4).

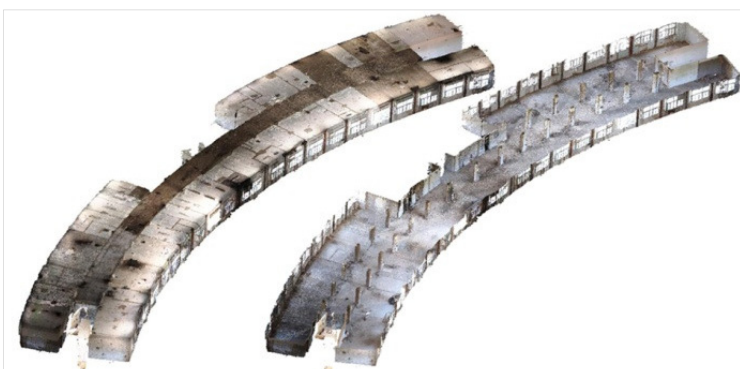

Figure 3: Axonometric view of the point cloud of a standard level. On the left the total result, on the right the sectioned result in the horizontal plane.

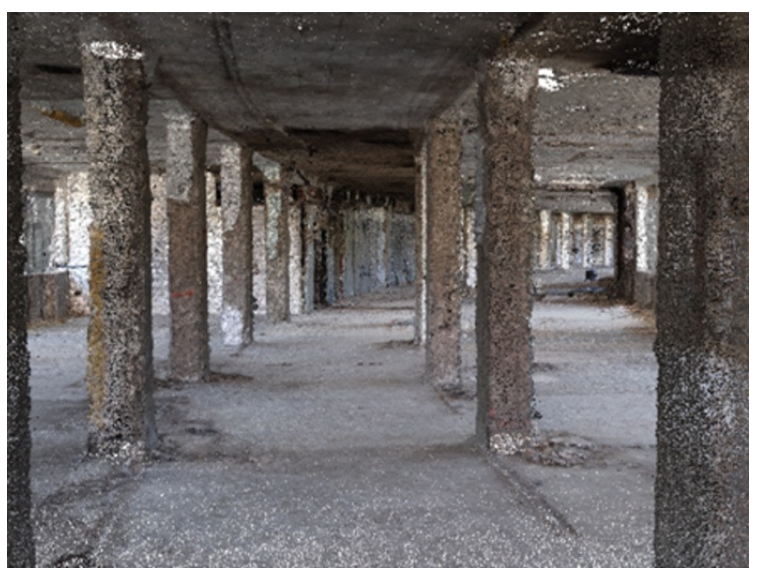

Figure 4: Internal view of a point cloud of a standard level.

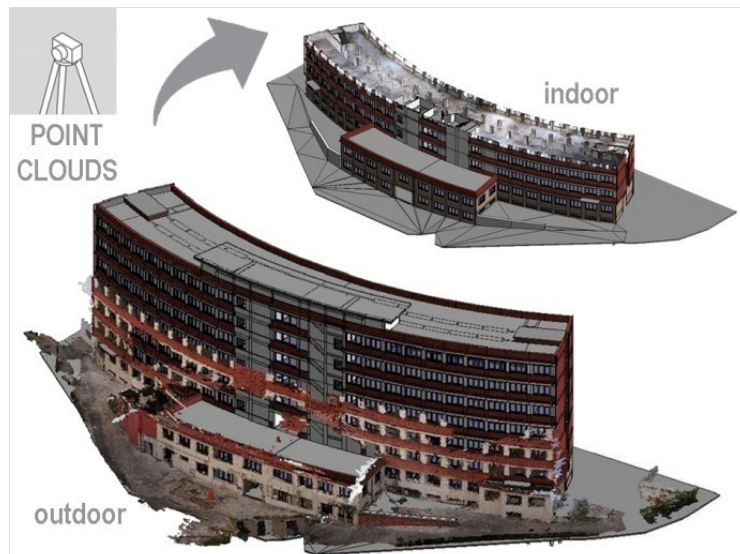

Figure 5: Point clouds imported into Autodesk Revit environment.

\section{FROM DATA TO MODELING}

\subsection{The hierarchy of elements and the classification of the} parts

After data capture and verification, the elements composing the entire artifact were cataloged so as to establish a hierarchy of family categories, families and typologies, namely the elements which characterize Autodesk Revit modeling.

Therefore, a list was created, in conformity with the features of SW in use, since family categories include all the elements belonging to a particular function - such as the ensemble of doors, windows, and walls -, families are a subgroup of the family category with particular morphological conditions, and typologies are the variations of a specific family which can be dimensional, materic or otherwise. The application of a single element to a certain position has his identification code. Families and their typologies have been modeled in an environment other than the project environment and only subsequently they have been imported in this latter.

Data organization is has been of primary importance. This activity was developed before modeling, considering that its accuracy influences processing times, the quality of the final product and the understanding of the entire project.

\subsection{Modeling of the elements in family environment}

After the recognition of the abacus, single elements to be modeled in family environment were identified.

The first step of model definition took into account structural and architectural elements such as plinths, beams, pillars, doors, and windows. Graphic information (geometry, size, material, etc.) and non-graphic information (identification data, load values, physical/energetic values, external links, etc.) were assigned to each element.

As regards the foundations (Figure 7), particularly the plinths, families and typologies were identified: elements with or without foundation piles, having a shape which can be of a truncated pyramid, rectangular, pentagonal or hexagonal, of different size and place at various altitudes.

Thereafter, it was necessary to establish the parameters for implementing information for each individual element, once it has been imported into the project. Some labels were created to insert the same identification numbers of archive data or some URLs to link, through a database, project details such as reinforcements and works of a general layout (Figure 6). As regards pillars, different loads were indicated for each individual level and column. The windows were also divided according to families and typologies, entering thermal values, profile and opening details.

This approach was therefore used for all the building elements which were gradually imported in a project environment.

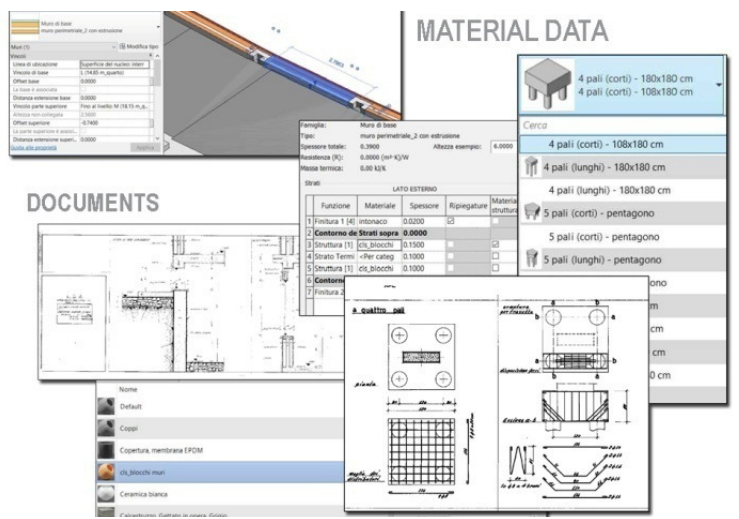

Figure 6: Work screens in a Revit environment and digitalized paper documents. 
5.3 The import in a project environment and the organization of architecture, structure, and installations

Before entering elements in a project environment, a reference file was created to record information on the whole building such as its name, its place, its orientation and graphic templates. The first step involves the design of a pillar grid of a standard level, taking into account the previous comparison of paper and survey data. Once the reference measurements were established in the plan, it was possible to identify the levels, as the main vertical reference, and finally, vector data of all the levels were imported in the respective altitudes.

After the project file has been defined, the individual elements were inserted, starting from the structural ones and then entering the architectural ones, by adding information such as the photos of the state of conservation of a particular element.

It should be specified that Autodesk Revit was used as reference software, so ceiling and wall elements are part of the "system" families, they cannot be uploaded from outside and therefore they were defined inside the project area.

The model was not created through a mechanical addition of previously processed elements, but according to a punctual evaluation of the relations between the parts, their correspondence and the verification of interferences.

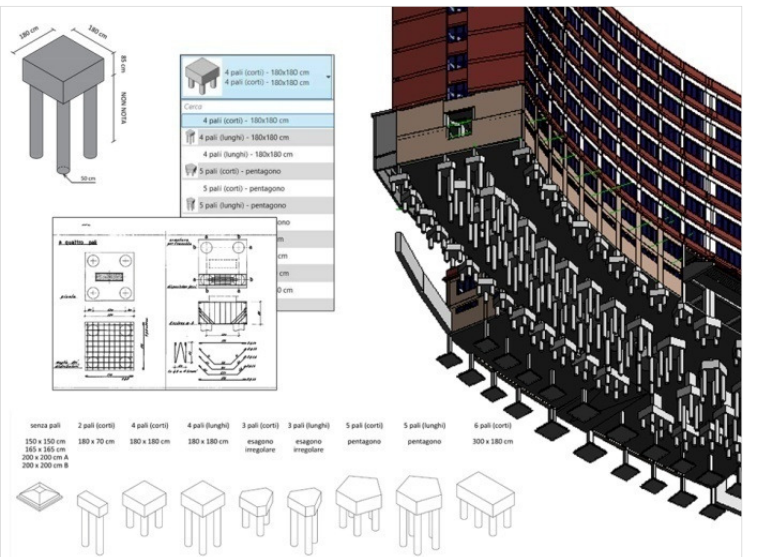

Figure 7: Organization of families and typologies of plinths.

In order to obtain a more lightweight and manageable file, a central model was created to be linked to the files of thematic models (structural, architectural, plant models). In particular, the plant model was connected with the project of the mechanical, electric, hydraulic and fire fighting equipment. Thereafter, the architectural system and the structural one were united (Figure 8) in order to remove the volumetric space occupied by structures from the walls.

\subsection{Naming elements and LOD}

In order to create an immediate and understandable file, a naming was defined both for files and for construction elements. It has been decided to choose a denomination taking into account several aspects and, in particular, for the files: Name project_role/system_subsystem_advancement

1. USNH_central

$$
\begin{aligned}
& \text { 1.1. USNH_structural } \\
& \text { 1.2. USNH_architectural } \\
& \text { 1.3. USNH_plants }
\end{aligned}
$$

$$
\text { 1.3.1. USNH_systems_airconditioning }
$$

\subsubsection{USNH_systems_elettric \\ 1.3.3. USNH_systems_hydraulic}

(USNH = US Navy Hospital)

While the elements belonging to a type:

function_material_dimension

\begin{tabular}{c|cc}
\hline category & family & type \\
\hline foundations & plinths & rc_piles_180x180 cm \\
pillars & square & rc_30x30 cm \\
beams & rectangular & rc_30x40 cm \\
floors & structuralceiling & rc_type A_24 cm \\
walls & wall & perimetral_40 cm \\
windows & 3 modules & $120 \times 180 \mathrm{~cm}$
\end{tabular}

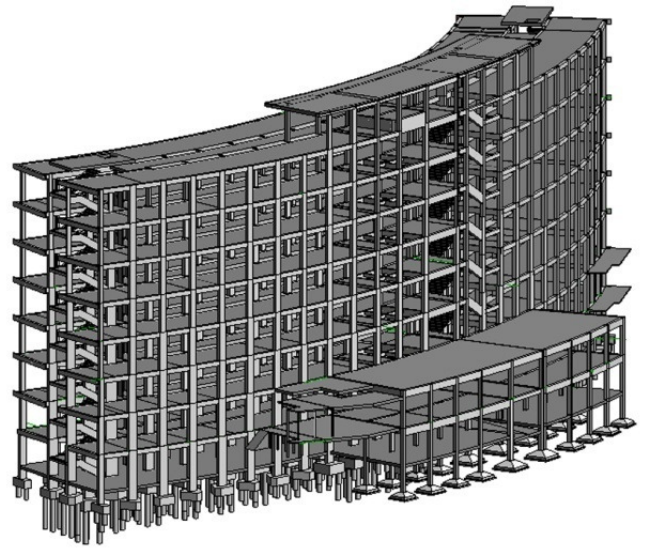

Figure 8: Structural model.

In respect of the degree of definition of the elements, reference Italian regulation is UNI 11337-4:2017: these rules make a distinction between LOD, LOG, and LOI. The LOD is the level of development of the objects and is divided into LOG (level of development of geometric attributes) and LOI (level of development of information attributes). In this case study, the degree of information for the elements can be attributed to LOD $\mathrm{C}$, entities are graphically displayed and qualities and quantities are definite.

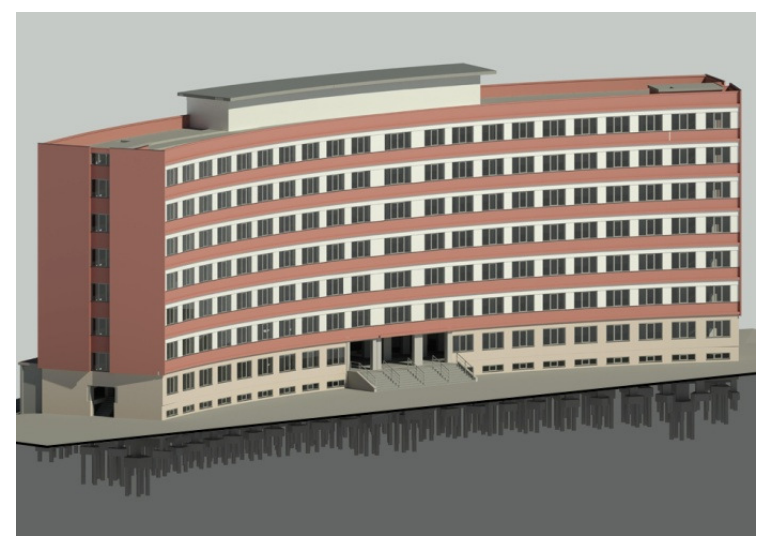

Figure 9: Frontal view of the architectural model. 


\section{CRITICAL ISSUES}

The main problems of modeling are due to some fundamental matters concerning the recognition and the evaluation of the parts and elements and their relations, especially the possibility to overcome or avoid the obstacles of technical implementation. In this case, even though the building is existing, problems connected with the inadequacy of information needed for BIM modeling of built architecture were previously overcome because it was also possible to obtain data which are not normally visible. Differently, in most cases, when the structure can't be directly inspected, data interpretation is entrusted to the cognitive and critical aptitude of the researcher in order to find solutions which are presumably suitable to construction typology or to the artifact features and history.

In this modeling, different data were integrated and organized by correctly facing the various problems.

In particular, on the one hand the structure of this building, characterized by a scarcely accentuated angle of curvature, facilitated texts for the acquisition of images during the survey, in the modeling phase. On the other hand, not allowing the recognition with pillars, it required finding a specific solution because it determined a disabling deformation since it didn't enable an automatic union (Figure 10). For this reason, beams were individually cut at their edges and light offsets were carried out in the plane $(\mathrm{x}, \mathrm{y})$ from the real position of the beam axis to avoid undesired deformations.

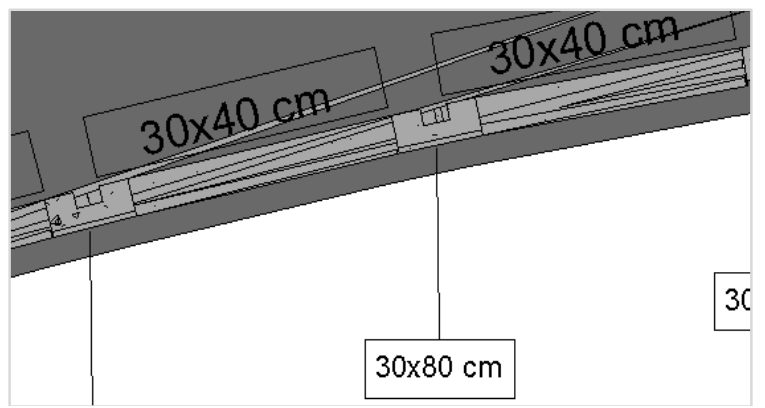

Figure 10: Graphic error in entering beams.

Some specific choices were taken both about the classification of some elements and about modeling procedures. In particular, regarding classification, the window panels (thin panels in reinforced concrete placed upon openings to close the space) required specific solutions because of a sort of ambiguity that software could detect. In fact, if classified as smaller beams, these elements would have generated a double beam for each span of the structural model. Since they don't play a structural role, they were incorporated in the wall as an extrusion, not only because they create a fixed protrusion on the wall below, but also because in this way the union of other elements can be avoided and distances can be easily controlled and kept homogeneous.

As regards modeling, in order to rapidly manage the windows recessed in the wall, it was decided to set inside the window an empty volume able to configure shape changes of the wall.

Actually, every problem could be solved in different ways, so the objective determines the choice of a solution more than another. Obviously, the objective is not only the creation of a model (database, analysis, etc.) but also its management, in order to reduce the creation of elements to the essential so as to avoid an excess of information and to allow a more immediate use also to the following user.

\section{MODELING}

\subsection{Air conditioning system}

After the creation of the structural and architectural model, attention has moved on the elements characterizing the functionality of the building starting the plant modeling with procedures similar to the BIM applied to the new construction. Also in this case, it is a model mainly useful to interrogation but, while the creation of an architectural and structural model involves a passage of information from the existing to the digital since plants were projected ex-novo, project papers were sufficient. The latter contain key information such as the position of the technical equipment and of the pipe network as well as dimensional and performance data.

The structural/architectural base is a guideline to determine the position of the elements which in turn will be defined according to the information requirements for management, such as the numbering of fancoils, the spaces they cover, their power and the energy absorbed, etc.. System pipes were placed to enable their identification once the work has finished, by defining the main machines, the size and nomenclatures of vertical mullions and the distribution of flow and return plan (Figures 11-12).

Also in this case, the slightly curvilinear shape of the building caused some problems in placing the "rigid" pipes for the difficulty of controlling the junctions in order to reduce interferences. Since data positioning and nomenclature are more important of the real form, it was decided to use a kind of "flexible" pipe more suitable for the curvilinear shape and to specify this adaptation in the typological tab to avoid misunderstandings in management and maintenance. In fact, the nature of the BIM model as a shared work platform is one of the reasons why it is necessary to organize the model in a clear way and to point out all the inconsistencies with the real building.

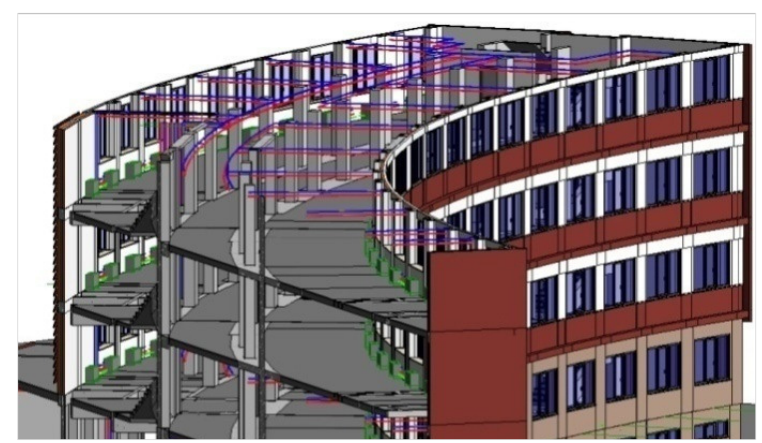

Figure 11: Cross-section with the view of the fan coil power supply system.

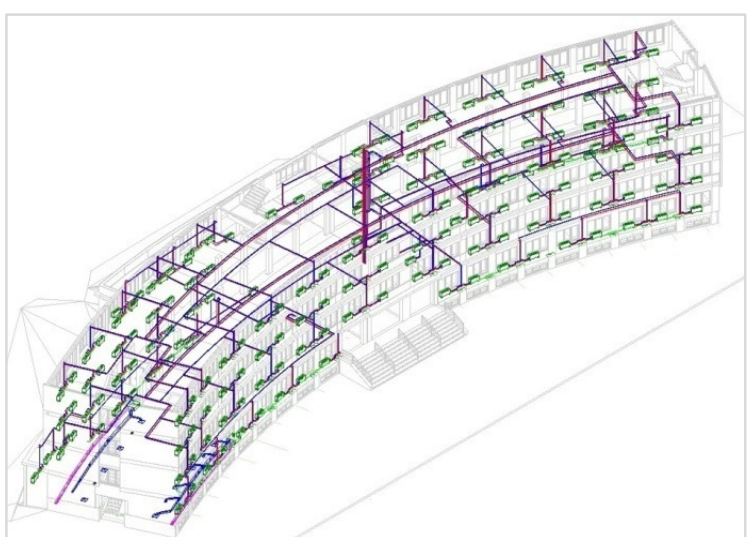

Figure 12: Axonometric sectioned view of fan-coil distribution between the ground floor and third floor. 


\section{CONCLUSIONS}

If it is necessary to organize a model clearly for communication between modelers taking part into its construction, it is equally important to assure the final user easy access to information. To this effect, such displays as Autodesk A360 allow to easily visualize and interrogate a model, to access lists and archive documents. In this respect, the building site pictures and archive paper documents have been digitalized thus creating links to the individual elements of the model, allowing to access to a complete database, including documents on the original executive project, the construction and the model itself.

This research revealed that present tools for BIM modeling even in the case of buildings characterized by serial elements are not yet sufficiently flexible and able to adapt to the features of what is already built and, from time to time, they require to find precise solutions to the various problems.

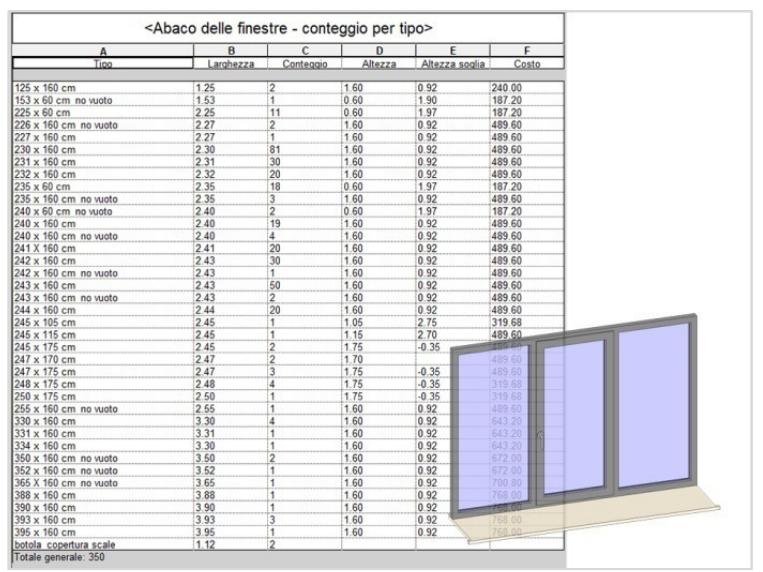

Figure13: List of windows.

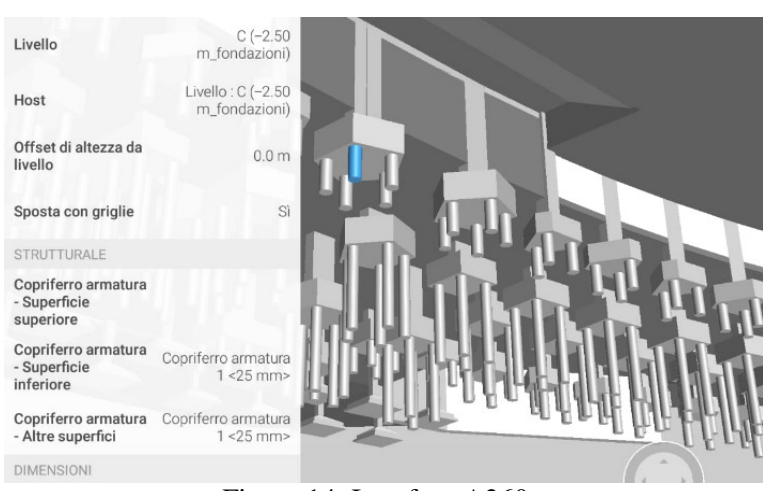

Figure 14: Interface A360.

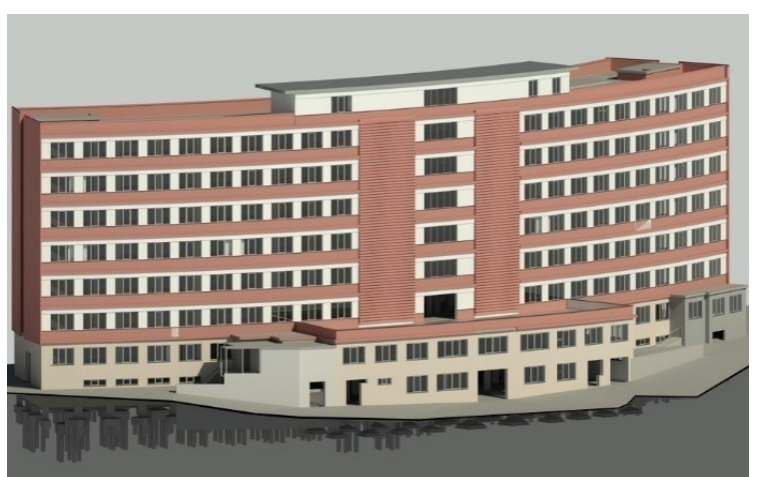

Figure 15: View of the rear of the architectural model.

\section{ACKNOWLEDGMENTS}

This work, still underway, is the result of a synergistic collaboration with "Ingg.Loy-Donà \& Brancaccio L.D.B. SPA". We would like to thank the individual designers and the representative figures of the company who have followed the work during the differents phases.

\section{REFERENCES}

Dallagiacoma, M., Valutazione di precisione, accuratezza $e$ qualità di modelli tridimensionali da elaborazione fotogrammetrica. 2016 in www.rilievoditigale.com.

De Luca, L., 2011. La fotomodellazione architettonica. Rilievo, modellazione, rappresentazione di edifici a partire da fotografie. Palermo: Dario Flaccovio, 2011, 264 p.

Dore, C., Murphy, M., 2017. Current state of the art Historic Building Information Modeling, Int. Arch. Photogramm. Remote Sens. Spatial Inf. Sci., XLII-2/W5, 185-192, https://doi.org/10.5194/isprs-archives-XLII-2-W5-185-2017, 2017.

Eastman C., Teicholz P., Sacks R., Liston K., 2011. BIM Handbook: A Guide to Building Information Modeling for Owners, Managers, Designers, Engineers and Contractors, 2nd Edition.

Logothetis, S., Delinasiou, A., Stylianidis, E.,2015. Building Information Modeling for Cultural Heritage: A review. ISPRS Ann. Photogramm. Remote Sens. Spat. Inf. Sci. Volume II5/W3, 2015, 177-183.

Oreni D., Brumana R., Georgopoulos A., Cuca B., 2013. HBIM for conservation and management of built heritage: towards a library of vaults and wooden bean floors. In ISPRS Annals of the Photogrammetry, Remote Sensing and Spatial Information Sciences, Volume II-5/W1, 2013.

Oreni D., Brumana R., Georgopoulos A., Cuca B., 2014. HBIM Library Objects for Conservation and Management of Built Heritage. In International Journal of Heritage in the Digital Era, Volume III, number 2, 2014.

Quattrini R., Malinverni E. S., Clini P., Nespeca R., Orletti E., 2015. From TLS to HBIM. High quality semantically-aware $3 D$ modeling of complex architecture. In International Archives of the Photogrammetry, Remote Sensing and Spatial Information Sciences, Volume XL-5/W4, 2015.

Remondino, F., El-Hakim, S.F., 2006. Image-Based 3D Modelling: A Review. Photogramm. Rec. J. 2006, 21, 269-291.

Osello A., 2015 BIM - GIS - AR per il FM. Dario Flaccovio Editore.

Scandurra S., Pulcrano M., Tarantino C., di Luggo A., 2017. Modellazione H-BIM e ricostruzione delle trasformazioni del costruito storico. In DN Building Information Modeling, Data $\&$ Semantics, number 1 . 